\title{
Instituições armadas, gênero e poder: reflexões para a transformação
}

\author{
Gênero e instituições armadas.
}

MOREIRA, Rosimeri; SCHACTAE, Andréa Mazurok (Orgs.).

Guarapuava: Editora UNICENTRO, 2016.

Os debates sobre questões de gênero dentro de instituições armadas têm ganhado força nas últimas décadas no Brasil. Foram diversas conquistas e avanços em busca da equidade de gênero e pelo fim da discriminação contra homossexuais. Em 2005, por exemplo, a Comissão de Constituição e Justiça e Cidadania da Câmara dos Deputados aprovou o Projeto de Lei 2773/ $00^{\prime}$, que exclui a referência à pederastia no Código Penal Militar, em função da inconstitucionalidade do artigo, o qual discriminava homossexuais. Em 2014 a primeira turma de mulheres na Escola Naval do Rio de Janeiro contava com 11 alunas ${ }^{2}$; antes disso, as mulheres ocupavam somente cargos administrativos ou na área de saúde, em serviços médicos e odontológicos.

Apesar das conquistas, seja em âmbito estadual, nas polícias militares, ou em âmbito nacional, no Exército, na Marinha e na Aeronáutica, a identidade institucional dessas corporações ainda é profundamente masculina e heteronormativa, desde a formação teórica até as práticas cotidianas. Por isso, debater sobre as fronteiras entre os discursos e práticas, entre as relações de gênero e de poder, é essencial para que os avanços continuem a acontecer $e$ que ocorram de maneira mais profunda, nos valores e ideologias da caserna.
Nesse sentido, o livro Gênero e instituições armadas, resultado do Simpósio Temático "Gênero, Diversidade e Instituições Armadas", realizado durante o Seminário Internacional Fazendo Gênero 10: Desafios Atuais dos Feminismos, no ano de 2013, na Universidade Federal de Santa Catarina, contribui para problematizar e refletir sobre essas questões. Organizado por Rosemeri Moreira e Andréa Mazurok Schactae, os textos procuram pensar as instituições armadas pelo viés do gênero, buscando problematizar a naturalização da relação entre militarismo e o masculino.

Entre as autoras, encontramos mulheres que ałuam em uma instituição militar, seja na Polícia Militar ou no Exército, e compreendem este espaço a partir de suas ocupações e de suas vivências. A partir de uma perspectiva feminista e militante, as discussões propostas visam, além de pensar a incorporação de mulheres nas instituições armadas, refletir sobre como as questões de gênero estão ligadas à violência, às armas e à guerra são sempre associadas ao masculino e negadas ao feminino.

Ao longo dos séculos, muitas mulheres estiveram envolvidas em confrontos e pegaram em armas, mas pouco se sabe sobre elas. Este livro procura se aprofundar nesta lacuna, discutindo a incorporação de mulheres nas polícias militares, em São Paulo, no Paraná e na Paraíba: a questão da internacionalização das polícias relacionada à incorporação de mulheres; a participação das mulheres no exército; a formação de soldadas/os pensada pelo viés de gênero; a construção de uma heroína na Revolução Cubana; e os discursos jurídicos a respeito das relações de gênero nas forças armadas.

Andréa Mazurok Schactae, doutora em História pela Universidade Federal do Paraná, abre o livro com o texto "'A gloriosa Polícia Militar 
do Paraná': masculinidade e identidade institucional". A autora analisa de que maneira é construída a identidade da Polícia Militar do Paraná, através dos discursos publicados nos boletins diários da instituição (entre 1927 e 2000), principalmente os de solenidades em datas comemorativas. O texto mostra que, apesar das mulheres conseguirem um espaço dentro da corporação, a identidade da polícia militar ainda é masculina e vinculada à honra dos guerreiros do passado, uma masculinidade idealizada que tanto norteia a construção da identidade institucional como é norteada por essa.

Rosemeri Moreira, doutora em História pela Universidade Federal de Santa Catarina, escreve o texto seguinte, "A invenção da mulher policial militar no Paraná", no qual discute como se deu, na década de 1970, a entrada das mulheres na Polícia Militar nesse Estado - a segunda corporação do país a permitir mulheres em seu quadro. Através de entrevistas e do olhar da imprensa local, a autora discute a ideologia maternalista presente nesta incorporação, os conflitos decorrentes da entrada das mulheres na caserna e suas atribuições, em geral desmilitarizadas e vinculadas ao cuidado do outro.

Em "A naturalização do gênero através do direito: notas para uma análise das instituições armadas", Laís Godoi Lopes e Carolina Nasse Cury, ambas mestrandas do Programa de PósGraduação da Faculdade de Direito das Universidade Federal de Minas Gerais, fundamentam a dissolução da ideia de identidade de gênero tradicionalmente assumida pelo direito. Através de um olhar sobre as instituições armadas, as autoras demonstram como o Exército e Polícias ainda são resistentes à igualdade de gênero, ao reconhecimento da diversidade sexual e como as normas e práticas jurídicas produzem rótulos e enquadram as pessoas em categorias heteronormativas.

No texto de Iris Oliveira do Nascimento, mestra em Educação pela Universidade Federal da Paraíba e Tenente Coronel da Polícia Militar da Paraíba, e de Maria Eulina Pessoa de Carvalho, doutora em Educação, intitulado "Competências de soldado: representações e percepções de alunas e alunos do curso de formação de soldados da Polícia Militar da Paraíba", investigam as competências de gênero atribuídas às soldadas e aos soldados, tendo como foco o Curso de Formação de Soldados, desenvolvido entre setembro de 2011 a julho de 2012 na Polícia Militar da Paraíba. As autoras procuram evidenciar as construções de gênero idealizadas pelo currículo e de que maneira estas são subjetivadas por homens e mulheres ao ingressarem na corporação.

Já Carla Christina Passos, doutora em Estudos Interdisciplinares sobre Mulheres, Gênero e Feminismos pela Universidade Federal da Bahia e Tenente Coronel Enfermeira do Quadro Complementar de Oficiais, em seu texto "Dos discursos às práticas das relações de gênero na caserna", procura explorar as fronteiras entre discursos e práticas do Curso de Formação de Oficiais (CFO) da Escola de Formação Complementar do Exército, do Instituto Militar de Engenharia e da Escola de Saúde do Exército Brasileiro. Através de 70 entrevistas com alunas/os e instrutoras/es, realizadas entre 2011 e 2012, a autora analisa como se desenvolvem as relações de gênero e poder no ambiente militar. São percebidas estratégias de negociação envolvendo as questões de gênero, a disciplina e a hierarquia onde as mulheres, ao ocuparem espaços antes somente masculinos, desestabilizam essa universalidade hegemônica, transformando-os e ressignificando-os.

Andréa Mazurok Schactae, em "'Mulheres guerreiras': mulheres na guerrilha cubana e a construção da heroína Célia Sanchez", procura refletir sobre a construção da heroína Célia Sanchez, através de biografia publicada na Revista Mujeres, logo após sua morte, em 1980. Apesar de ocupar um espaço tido como masculino, rompendo com o ideal de feminilidade, em sua biografia são destacadas suas preocupações com o povo, colocando-a como uma figura que cuida das pessoas, mas também combate. Outro aspecto da biografia é que a conecta ao imaginário da maternidade e, consequentemente, ao que se espera do feminino. Desse modo, encarnando a face feminina do Estado Cubano a imagem de Célia Sanchez é delineada de modo a reproduzir um ideal de feminilidade, mesmo quando guerreira, e legitimar, neste contraste, o ideal de masculinidade.

Em "Internacionalização das polícias e o policiamento feminino paulista: a viagem da Comandante Hilda Macedo aos EUA", Rosemeri Moreira discute a internacionalização das polícias, na década de 1950, pensando o lugar do policiamento feminino no Ocidente. Acompanhando a viagem de Hilda Macedo, primeira mulher comandante do, então, chamado policiamento paulista, a partir de relatórios oficiais, a pesquisadora percebe $\circ$ projeto estadunidense a ser exportado para a América Latina, focado nas mulheres e com um caráter assistencial " modelo que seria incorporado pelas mulheres que ingressaram nas polícias em todo o país. 
Por fim, os textos evidenciam que as instituições armadas ainda são lugares masculinos, ligados à virilidade e à honra, mas a presença cada vez mais significativa e numerosa de mulheres tende a desestabilizar essa hegemonia, provocando reflexões dentro e fora dos quartéis e propondo mudanças na forma como estas instituições constroem suas relações de poder e de gênero. Ainda que as transformações ocorram mais no discurso que na prática, o caminho para outras formas de organização e de pensamento já começou e muito já foi conquistado. Nesse sentido, este livro contribui para a consolidação deste debate tão importante no contexto brasileiro.

\section{Notas}

'A Ficha de tramitação completa desse Projeto de Lei pode ser acompanhada através do site da Câmara dos Deputados, disponível on-line em http://www.camara.gov.br/ proposicoesWeb/fichadetramitacao?idProposicao $=18609$. Acesso em 15/10/2016.

${ }^{2}$ BRASIL, Ministério da Defesa. Primeira turma de aspirantes mulheres ingressa na mais tradicional escola militar do país. Brasília, 07/02/2014. Disponível on-line em http:// www.defesa.gov.br/noticias/8447-defesa-primeira-turmade-aspirantes-mulheres-ingressa-na-mais-tradicionalescola-militar-do-pais. Acesso em 15/10/2016.

\section{Referênclas}

BRASIL, Ministério da Defesa. Primeira turma de aspirantes mulheres ingressa na mais tradicional escola militar do país. Brasília, 07/02/2014. Disponível on-line em http://www.defesa.gov.br/noticias/ 8447-defesa-primeira-turma-de-aspirantesmulheres-ingressa-na-mais-tradicionalescola-militar-do-pais. Acesso em 15/10/2016.

MOREIRA, Rosimeri; SCHACTAE, Andréa Mazurok (Orgs.). Gênero e instituições armadas. Guarapuava: Editora UNICENTRO, 2016.

[Recebida em 20/10/2016 e aceita em 07/02/2017]

Fernanda Arno

Universidade Federal de Santa Catarina, Florianópolis, Santa Catarina, Brasil

Fernanda Arno (fernanda.arno@gmail.com) é doutoranda do Programa de Pós-Gradua-ção em História da Universidade Federal de Santa Catarina e Mestra em História pela Universidade Federal de Santa Catarina. Atualmente, pesquisa a construção de masculinidades, relações de poder e subjetividades na Polícia Militar de Santa Catarina, na década de 1960. 